\title{
Assessment of Distribution Network Planning Based on Dynamic Weighted Particle Swarm Algorithm with Distributed Generation and Energy Storage
}

\author{
Ming Zeng ${ }^{1}$, Yuanfei $\mathrm{Li}^{1}$, Yiqun Liu ${ }^{1, *}$, Xu Han ${ }^{1}$, Shiyu Meng ${ }^{1}$, Jinyue Dou ${ }^{1}$ and Chenjun Sun ${ }^{2}$ \\ ${ }^{1}$ School of Economics and Business Management, North China Electric Power University, China \\ ${ }^{2}$ State Grid Hebei Power Company, State Grid Corporation of China, China \\ *Corresponding author
}

\begin{abstract}
The Coordination Planning of distribution network with distributed generation and energy storage is a hot research topic at home and abroad. This paper proposes a multi objective programming model with minimum investment cost and minimum annual operating cost as the objective function; the uncertainty of wind power and photovoltaic power generation is simulated by Monte Carlo sampling; the multi-objective programming model is solved by using the dynamic weighted particle swarm algorithm, and the optimal Pareto is achieved; the results show that he proposed method can meet the demand of regional power network load and the requirements of the network, at the same time, effectively reduce the economic costs of the distribution network.
\end{abstract}

Keywords-distributed generation; dynamic weighted particle swarm algorithm; assessment

\section{INTRODUCTION}

In recent years, the distributed generationhas been rapid development. However, distributed wind power and photovoltaic power has great randomness, which is harmful to the stable operation of power system[1]. With the series of transformation and reform of China's energy and electric power industry, it is expected that all kinds of distributed power and energy storage will gradually penetrate into the existing distribution network system[2]. Therefore, the research on the coordination planning method of distribution network with distributed generation and energy storage has become a hot research topic at home and abroad.

This paper puts forward a coordination planning method of distribution network with distributed generation and energy storage based on dynamic weighted particle swarm algorithm. First, a multi-objective programming model with the minimum investment and annual operating cost as the objective function is proposed, using Monte Carlo sampling to simulate the uncertainty of wind power and photovoltaic power generation; second, the multi-objective programming model is solved by using the dynamic weighted particle swarm algorithm to achieve the Pareto optimal; finally, solve the problem of the transforming IEEE33 node system. The results show that the proposed method can meet the demand of regional power network load and the requirements of the network, and effectively reduce the economic costs of the distribution network.

\section{A PLANING MODEL CONSIDERING THE UNCERTAINTY OF} DG OUTPUT

\section{A. Objective Function}

In this paper, the optimal planning model has two objective functions:

$$
\operatorname{minC}_{1}=\min \left[\sum_{\forall_{\mathrm{p}}} \mathrm{P}_{\mathrm{p}}+\sum_{\forall_{\mathrm{w}}} \mathrm{P}_{\mathrm{w}}+\sum_{\forall_{\mathrm{ge}}} \mathrm{P}_{\mathrm{ge}}+\sum_{\forall_{\mathrm{s}}} \mathrm{P}_{\mathrm{s}}\right]
$$

$\mathrm{P}_{\mathrm{p}}, \mathrm{P}_{\mathrm{w}}, \mathrm{P}_{\mathrm{ge}}$ and $\mathrm{P}_{\mathrm{s}}$ are distributed photovoltaic, wind power, gas internal combustion generators and energy storage equipment costs.

$$
\begin{aligned}
& \operatorname{minC}_{2}=\min \left[\mathrm{r}_{\text {grid }} \mathrm{E}_{\text {grid }}+\sum_{\forall_{\mathrm{p}}} \mathrm{r}_{\mathrm{p}} \mathrm{E}_{\mathrm{p}}+\right. \\
& \left.\sum_{\forall_{\mathrm{w}}} \mathrm{r}_{\mathrm{w}} \mathrm{E}_{\mathrm{w}}+\sum_{\forall_{\mathrm{ge}}} \mathrm{r}_{\mathrm{ge}} \mathrm{E}_{\mathrm{ge}}+\sum_{\forall_{\mathrm{s}}} \mathrm{C}_{\mathrm{s}}\right]
\end{aligned}
$$

$\mathrm{C}_{2}$ is annual operating cost; $\mathrm{r}_{\text {grid }}$ and $\mathrm{E}_{\text {grid }}$ are the price and quantity of electricity to the main network; $r_{p}$ and $E_{p}$ are electric power cost of distributed photovoltaic power generation and annual distributed photovoltaic power generation; $r_{w}$ and $E_{w}$ are electric power cost of distributed wind power and distributed photovoltaic power generation; $r_{g e}$ and $E_{\text {ge }}$ are the power cost and annual power generation of distributed small scale gas combustion engine, $\mathrm{C}_{\mathrm{s}}$ is annual operation and maintenance cost of energy storage.

\section{B. Constraint Conditions}

1) Node voltage constraints

$$
\mathrm{U}_{\mathrm{imin}} \leq \mathrm{U}_{\mathrm{i}} \leq \mathrm{U}_{\text {imax }} \quad \mathrm{i}=1,2, \ldots, \mathrm{n}
$$

$\mathrm{U}_{\mathrm{i}}$ is the voltage of the node $\mathrm{I}$; the upper and lower bounds of the node voltage are expressed as $\mathrm{U}_{\mathrm{imin}}$ and $\mathrm{U}_{\mathrm{imax}}$.

2) Branch transmission power constraints

$$
\mathrm{P}_{1} \leq \mathrm{P}_{\operatorname{lmax}} \quad \mathrm{l}=1,2 \ldots, \mathrm{n}
$$

$\mathrm{P}_{1}$ is the transmission power of the branch 1; $\mathrm{P}_{1 \max }$ is the upper limit of the transmission power of the branchl. 
3) Tidal current constraints

$$
\left\{\begin{array}{l}
P_{i}=V_{i} \sum_{j=1}^{n} V_{j}\left(G_{i j} \cos \theta_{i j}+B_{i j} \sin \theta_{i j}\right) \\
Q_{i}=V_{i} \sum_{j=1}^{n} V_{j}\left(G_{i j} \sin \theta_{i j}-B_{i j} \cos \theta_{i j}\right)
\end{array}\right.
$$

$\mathrm{P}_{\mathrm{i}}$ and $\mathrm{Q}_{\mathrm{i}}$ are the active and reactive power injected by the node $I ; V_{i}$ is the electric voltage amplitude of the node I; $G_{i j}$ is the branch conductanceis; $\mathrm{B}_{\mathrm{ij}}$ is the branchsusceptanceis; $\mathrm{jis}$ the voltage phase angle difference between the node I.

4) Power supply capacity constraints

$$
\sum_{\mathrm{k}=1}^{\mathrm{n}} \mathrm{P}_{\mathrm{k}} \eta_{\mathrm{k}}>1_{\mathrm{e}}
$$

$\mathrm{P}_{\mathrm{k}}$ is the real time output of the generator group $\mathrm{k} ; \mathrm{l}_{\mathrm{e}}$ is the real time electric load of the system; $\eta_{k}$ is the variable between $0-1$, expressing the start-stop status of the unit.

5) Energy storage output constraints

$$
\left\{\begin{array}{c}
\mathrm{R}_{\min }^{\mathrm{i}} \leq \mathrm{r}_{\mathrm{k}}^{\mathrm{i}} \leq \mathrm{R}_{\max }^{\mathrm{i}} \\
\mathrm{SOC}_{\min } \leq \mathrm{SOC}_{\mathrm{t}} \leq \mathrm{SOC}_{\max } \\
\mathrm{r}_{\mathrm{k}, \mathrm{t}}^{\mathrm{i}} \leq\left(\mathrm{SOC}_{\mathrm{t}-1}-\mathrm{SOC}_{\min }\right) \mathrm{S}_{\max } \\
\mathrm{r}_{\mathrm{k}, \mathrm{t}}^{\mathrm{i}} \mathrm{t}_{\mathrm{i}, \mathrm{t}} \leq\left(1-\mathrm{SOC}_{\mathrm{t}-1}\right) \mathrm{S}_{\max }
\end{array}\right.
$$

$\mathrm{SOC}_{\text {min }}$ is the minimum state of charge of the energy storage device; $\mathrm{R}_{\max }^{\mathrm{i}}$ is the power rating of the energy storage device I; tis time period; $\mathrm{SOC}_{\mathrm{t}-1}$ is the state of charge between the time period $0-1 ; \mathrm{r}_{\mathrm{k}, \mathrm{t}}^{\mathrm{i}}$ is the charging and discharging power of the energy storage device $i$ in time section; $t_{i, t}$ is the charge and discharge time of the energy storage device $i$ in time section $\mathrm{t}$.

6) Total access of distributed power sourcesconstraints

$$
\sum_{\forall \mathrm{DG}} \mathrm{P}_{\mathrm{DG}} \leq 20 \% \times \mathrm{P}_{\text {new }}
$$

$\sum_{\forall D G} \mathrm{P}_{\mathrm{DG}}$ is the total installed capacity of the distributed power supply; $\mathrm{P}_{\text {new }}$ is the total amount of new load.

\section{Processing of the output Uncertainty of Wind Power and Photovoltaic Units}

\section{1) Wind power output simulation}

Statistics show that wind speed has statistical characteristics, which shows the partial normal distribution[3].In the project, Weibull curve is generally used to describe the wind speed distribution. On this basis, the probability density formula of the output power of the wind turbine is shown in the following formula:

$$
\left\{\begin{array}{c}
f\left(P_{w}\right)=\frac{K}{b C}\left(\frac{P_{w}-a}{b C}\right)^{K-1} \exp \left[-\left(\frac{P_{w}-a}{b C}\right)^{K}\right] \\
a=\frac{P_{w}^{\prime} v_{c}}{v_{c}-v_{c}^{\prime}} \\
b=\frac{P_{w}^{\prime}}{v_{c}-v_{c}^{\prime}}
\end{array}\right.
$$

$\mathrm{K}$ and Care the shape and scale parameters of the Weibull distribution; $\mathrm{P}_{\mathrm{w}}^{\prime}$ is the rated power of the wind turbine; $\mathrm{v}_{\mathrm{c}}$ and $\mathrm{v}_{\mathrm{c}}^{\prime}$ are the cut in wind speed and rated wind speed of the wind turbine.

2) Output power simulation of photovoltaic power generation

The output power of the photovoltaic power generation is the product of the light intensity, the photovoltaic cell panel area and the photoelectric conversion efficiency. Statistics show that the light intensity is approximate to the beta distribution in a certain period of time. The probability density formula of the output power of the photovoltaic power generation is shown in the following formula:

$$
f\left(P_{p}\right)=\frac{\Gamma(\rho+\lambda)}{P_{p, \max } \Gamma(\rho) \Gamma(\lambda)} \times\left(\frac{P_{p}}{P_{p, \max }}\right)^{\rho-1}\left(1-\frac{P_{p}}{P_{p, \max }}\right)^{\lambda-1}
$$

$\mathrm{P}_{\mathrm{p}, \max }$ is the maximum output power of the photovoltaic power array, $\rho$ and $\lambda$ are the shape parameters of the beta distribution.

\section{DyNAMIC Weighted PaRticle SWARM Optimization}

PSO (Particle Swarm Optimization) is a class of algorithm which starting from random solutions to find the optimal solution through Iterations [4]. Model in this article is a multi-objective optimization problem, however, the traditional PSO can only get one solution feedback, in order to solve the multi-objective optimization problem, we often find the solution through weighting each objective function into an overall objective function, then use the PSO.

Weighted dynamic multi-objective PSO algorithm used in this paper aggregates each objective function into an overall objective function $\mathrm{C}_{\mathrm{to}}$ by assigning weights $\omega_{\mathrm{u}}$ ( $\mathrm{u}$ is the target number) to them. Calculate the value of the particles $\mathrm{x}_{\mathrm{i}}$ in each iterative process $\mathrm{N}$ :

$$
\mathrm{C}_{\mathrm{to}}(\mathrm{N})=\sum_{\mathrm{u}-1}^{\mathrm{n}} \omega_{\mathrm{u}}(\mathrm{N}) \mathrm{f}_{\mathrm{u}}\left[\mathrm{x}_{\mathrm{i}}(\mathrm{N})\right]
$$

The formulas for the weights is:

$$
\left\{\begin{array}{c}
\omega_{\mathrm{c}_{1}}(\mathrm{~N})=|\cos (2 \pi \mathrm{N} / \xi)| \\
\omega_{\mathrm{c}_{2}}(\mathrm{~N})=1-\omega_{\mathrm{c}_{1}}(\mathrm{~N})
\end{array}\right.
$$

The formula for the update velocity of the particle is:

$$
v_{\mathrm{i}, \mathrm{N}+1}=\xi(\mathrm{N}) v_{\mathrm{i}, \mathrm{N}}+\mathrm{c}_{1} \mathrm{r}_{1}\left(\mathrm{P}_{\mathrm{i}}^{\mathrm{k}}-\mathrm{X}_{\mathrm{i}}^{\mathrm{k}}\right)+\mathrm{c}_{2} \mathrm{r}_{2}\left(\mathrm{P}_{\mathrm{g}}^{\mathrm{k}}-\mathrm{X}_{\mathrm{i}}^{\mathrm{k}}\right)
$$

$v_{i, N}$ is iteration velocity of the particle, $c_{1}$ andc $c_{2}$ are learning factors, their value is generally between $0-2 ; r_{1} a{ }^{2} r_{2}$ are random numbers between $0-1 ; P_{i}$ is the best location that particle $i$ experienced, $\mathrm{P}_{\mathrm{g}}$ is the best location in the experience of the swarm. The inertia constant $\xi(\mathrm{N})$ linearly decreases with iteration between $0-1$, which making the searched volume of the whole algorithm reduce with the iteration.

The formula of the particle position updating is: 


$$
\mathrm{P}_{\mathrm{i}, \mathrm{N}+1}=\mathrm{P}_{\mathrm{i}, \mathrm{N}}+\mathrm{V}_{\mathrm{i}, \mathrm{N}+1}
$$

By this calculation method, we can quickly exclude all infeasible system plan outside the feasible region, Thus speed up the convergence rate. The process of the algorithm is shown in Figure I.

We use the standard IEEE33 node system to test the case. IEEE33 Node system is shown in Figure II [6].

There are no power and energy storage in the current power distribution network system and all electricity needs are provided by the main network. All the nodes are allowed to configure the distributed power and energy storage except $1,3,5$.The grid connected switch of the main network remains closed, which allowing the distribution network systems purchase power from the main network as long as there is power shortage, but the extra power should be grounded at the

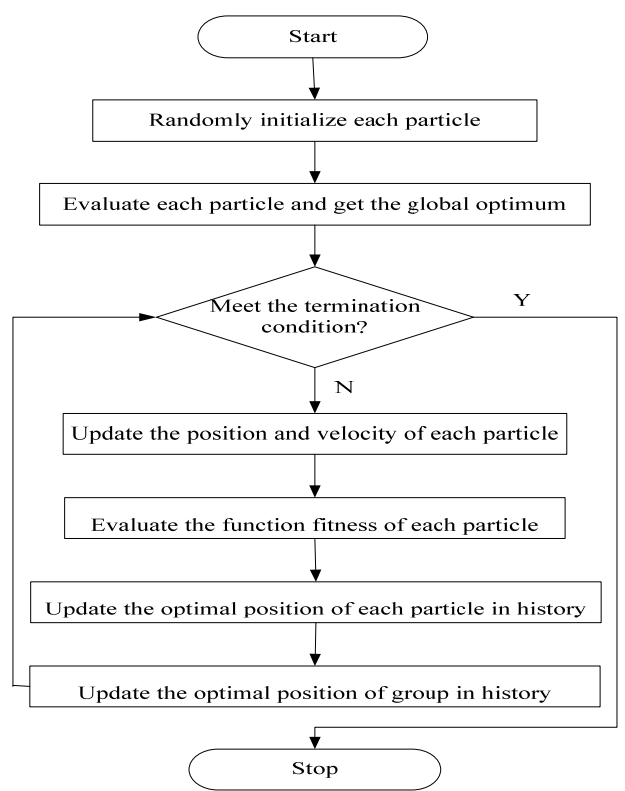

FIGURE I. DYNAMIC WEIGHTED PARTICLE SWARM ALGORITHM FLOWCHART

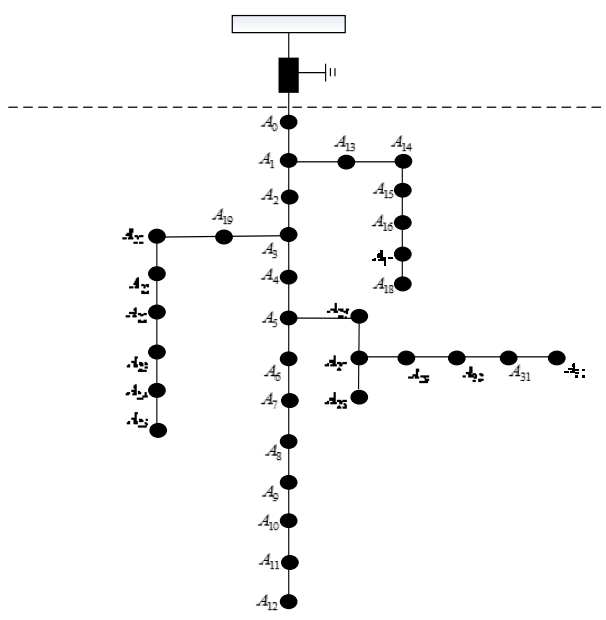

FIGURE II. IEEE33 NODE GRAPH

\section{CASE ANALYSIS}

Switch, and is not allowed to return to the main network.Other required data of the case is shown in Table I [7].

Substitute the above data and the basic parameters provided by IEEE Node system into dynamic Weighted PSO, the plan results are shown in Table II.

TABLE I. ANOTHER DATA NEEDED IN THE CASE

\begin{tabular}{|c|c|}
\hline Parameter name & Value (unit) \\
\hline Purchase price of the main grid power & $0.5 y u a n / \mathrm{Kh}$ \\
\hline The cost of the distributed wind power & 0.1 yuan/ KWh \\
\hline The cost of the distributed solar power investment & $27000 \mathrm{yuan} / \mathrm{KW}$ \\
\hline The cost of the storage investment & $1800 \mathrm{yuan} / \mathrm{KW}$ \\
\hline The cost of the gas engine investment & $15000 \mathrm{yuan} / \mathrm{KW}$ \\
\hline The cost of the distributed solar power & $1.15 \mathrm{yuan} / \mathrm{KWh}$ \\
\hline The cost of the energy storage operation & 1200 (yuan/ KWh) \\
& /year \\
\hline The cost of the distributed wind power investment & $7200 \mathrm{yuan} / \mathrm{KW}$ \\
\hline The cost of the gas engine power & $0.4 \mathrm{yuan} / \mathrm{KWh}$ \\
\hline
\end{tabular}

TABLE II. PLANNING RESULTS

\begin{tabular}{|c|c|c|c|}
\hline Number & Connecting node & Type & Parameter \\
\hline 1 & A4 & Solar power & $300 \mathrm{~kW}$ \\
\hline 2 & A6 & Energy storage & $250 \mathrm{~kW} \cdot \mathrm{h}$ \\
\hline 3 & A8 & Wind power & $500 \mathrm{~kW}$ \\
\hline 4 & A9 & Solar power & $300 \mathrm{~kW}$ \\
\hline 6 & A12 & Energy storage & $250 \mathrm{~kW} \cdot \mathrm{h}$ \\
\hline 8 & A15 & Solar power & $250 \mathrm{~kW}$ \\
\hline 11 & A19 & Solar power & $250 \mathrm{~kW}$ \\
\hline 12 & A21 & Wind power & $300 \mathrm{KW}$ \\
\hline 13 & A23 & Solar power & $300 \mathrm{~kW}$ \\
\hline 14 & A25 & Energy storage & $500 \mathrm{~kW} \cdot \mathrm{h}$ \\
\hline 16 & A28 & Solar power & $250 \mathrm{~kW}$ \\
\hline 19 & A32 & Energy storage & $500 \mathrm{~kW} \cdot \mathrm{h}$ \\
\hline
\end{tabular}

The comparison of the system cost before and after the panning is shown in Table III.

TABLE III. THE COMPARISON OF THE SYSTEM COST BEFORE AND AFTER THE PANNING

\begin{tabular}{|c|c|c|}
\hline & $\begin{array}{c}\text { Cost of investment } \\
\text { (ten thousand yuan) }\end{array}$ & $\begin{array}{c}\text { The annual operation cost } \\
\text { (ten thousand yuan) }\end{array}$ \\
\hline Before planning & 0 & 87 \\
\hline After planning & 247 & 49 \\
\hline
\end{tabular}

Without considering the time value of money, it is expected to achieve static equilibrium after putting all devices into production in the first seven years. It is much shorter than the life of the new equipment. Therefore, it is believable that the proposal proposed in this paper improve the economic efficiency of the power distribution network system.

\section{CONCLUSION}

In this paper, a multi objective programming model of distribution network system considering wind power and photovoltaic output uncertainty is proposed. By using the basic data of IEEE33 node and relevant supplementary data, a 
distribution network system planning and simulation are constructed. By using the model and algorithm constructed in this paper, the planning results of the distribution network system are obtained. Cost comparison shows that the proposed scheme can bring benefits to the distribution network system.

\section{ACKNOWLEDGMENT}

This paper is supported by State Grid science and technology projects-Study on the Distributed Generation Development Applicability Strategy Analysis and Evaluation.

\section{REFERENCES}

[1] CHEN Chiye, WEN Yafeng, LIU Zifa, et al. Comprehensive Evaluation Method of Distribution Network Including Various Types of Distributed Generation[J]. Electric Power Construction, 2015, 36(1): 128-135.

[2] YOU Yi, LIU Dong, YU Wenpeng. Technology and its trends of active distribution network[J]. Automation of Electric Power Systems, 2012,36(5): 9-25.

[3] WU Wanlu, WEI Gang, XIE Lirong, et al. Coordinated Planning of Distribution Network Containing Charging Station and Distributed Generation[J]. Power System Protection and Control, 2014, 42(15): 65-73.

[4] HUANG Ping. Improved Particle Swarm Algorithm and its Application in Power System[D]. South China University of Technology, Guangzhou, 2012.

[5] ZENG Ming, YANG Yongqi, XIANG Hongwei, et al. Optimal dispatch model based on coordination between "generation-grid-load-energy-storage" and demand-side resource[J]. Electric Power Automation Equipment, 2016, 36(2): 102-111.

[6] MARTINS V F, BORGES C L T, et al. Active distribution network integrated planning incorporating distributed generation and load response uncertainties[J]. IEEE Transactions on Power Systems, 2011, 26(4): $2164-2172$.

[7] ZENG Ming, PENG Lilin, FAN Qiannan, et al. Pareto Optimal Planning Model of Distribution Network with DG Based on COA-EO Hybrid Algorithm[J]. Electric Power Construction, 2015, 36(11): 1-9 